\title{
Implications of Academic Medicine's Failure to Recognize Clinical Excellence
}

\author{
Samuel C. Durso, MD, MBA; Colleen Christmas, MD; Steven J. Kravet, MD, MBA; \\ Gregory Parsons and Scott M. Wright, MD
}

\begin{abstract}
Objective: To better understand the implications of inadequately recognizing clinical excellence in academia by exploring the perspectives of clinically excellent faculty within prominent American departments of medicine.
\end{abstract}

Design: Qualitative study.

Setting: 8 academic institutions.

Participants: 24 clinically excellent department of medicine physicians.

Methods: Between March I and May 31, 2007, investigators conducted in-depth semi-structured interviews with 24 clinically excellent physicians at leading academic institutions. Interview transcripts were independently coded by two investigators and compared for agreement. Content analysis identified themes related to clinical excellence in academia.

Results: Twenty informants (83\%) were Associate Professors or Professors, 8 (33\%) were females, and the physicians hailed from a wide range of internal medicine specialties. The mean percent effort spent in clinical care by the physicians was $48 \%$. The five domains that emerged related to academic medicine's failure to recognize clinical excellence were: (I) low morale and prestige among clinicians, (2) less than excellent patient care, (3) loss of talented clinicians, (4) a lack of commitment to improve patient care systems, and (5) fewer excellent clinician role models to inspire trainees.

Conclusions: If academic medical centers fail to recognize clinical excellence among its physicians, they may be doing a disservice to the patients that they pledge to serve. It is hoped that initiatives aiming to measure clinical performance in our academic medical centers will translate into meaningful recognition for those achieving excellence such that outstanding clinicians may feel valued and decide to stay in academia.

Keywords: Academia; Patient care; Promotion

"Academic medicine does not only require good scientists and researchers, but good clinicians, who contribute immensely to clinical medicine and the translation of laboratory research into clinical practice... Those who are exceptional clinicians should be recognized as such and should have a role in academic medicine.... Unless we recognize those who spend most of their time looking after patients, we will lose them to the private sector and end up with a glut of researchers and no one to teach clinical skills and bedside medicine to the coming generation." 1

S.W. Yusuf, MD, MRCP

Corresponding Author: Scott Wright, MD, Johns Hopkins University School of Medicine, Johns Hopkins Bayview Medical Center, 5200 Eastern Avenue, Suite 2300, Baltimore, MD 2 I 224 USA, Tel: 4I 0-550-08 I 7, Fax: 4I 0-550-3403,

Email: swright@jhmi.edu
Received: March 26, 2009

Revised: June II, 2009

Accepted: June 17, 2009

doi: $10.3121 / \mathrm{cmr} .2009 .856$ 
$\mathrm{W}$ does not exist, the elements that contribute to a reputation for clinical excellence in academia have been described as first-rate communication and interpersonal skills, unfaltering professionalism and humanism, keen diagnostic acumen, skillful negotiation of the healthcare system, brilliant knowledge, scholarly approach to clinical care, and passion. ${ }^{2}$ There is no doubt that patients want clinically excellent care and trust that academic medical centers serve as the source for creating this prototype of physician. Over the last 100 years, academic medical centers (AMC) have received generous support from the public to fulfill this trust through the application of a tripartite mission: research, education, and patient care. ${ }^{3}$ Academic medical centers may not be equally committed to all three components of the mission as evidenced by the fact that promotion decisions are based predominantly on scholarly productivity. ${ }^{4}$

Among other factors including the differential in income potential between academia and the private sector, inadequate recognition and reward systems may be driving physicians that are deeply committed to clinical work away from academic medical centers. ${ }^{5}$ While expectations for achievement in research are well-defined, ${ }^{6-10}$ and efforts to standardize recognition for excellence in teaching are becoming more clear, ${ }^{4,11}$ a comparable measurement and reward structure for clinical excellence does not exist. To gain insight into clinical excellence, we conducted a qualitative study that explored perspectives of exceptional clinicians working in academic medical centers. In this paper, their perceptions about the impact of failing to recognize clinical excellence in academia are presented.

\section{METHODS}

\section{Study Design}

A qualitative study design was selected to allow for the emergence of themes that researchers may not have anticipated. Interviews were used, as they permit exploration in greater depth than may be possible with closed-ended scales, surveys, or even focus groups.

\section{Study Sampling}

Through purposive sampling, case finding was used to identify physicians with reputations for being clinically excellent within the top 10 departments of medicine according to the 2006 rankings from U.S. News and World Report. ${ }^{12}$ The department chairs at these 10 institutions were asked to name 5 physicians within their department judged to be the most clinically excellent. To help with their selection process, the following point of reference was included in the request: "In considering this, it may help to think about which of your faculty you would ask to care for a close family member who was ill (with a diagnosis within this physician's area of expertise)." From the lists of physicians, we randomly selected three physicians from each AMC to interview using www.random.org. If any of these physicians were unavailable or declined participation, we proceeded to the next physician from that institution on the random order list. The institutional review board approved the study.

\section{Data Collection}

From March 1 to May 31, 2007, two investigators conducted audio-taped, semi-structured one-on-one interviews lasting about 30 minutes with participants by phone. The interviewer began by asking closed-ended questions that collected demographic information, such as division and academic rank, before switching to open-ended questions about the clinical excellence in academia. The interviewers, trained in qualitative interviewing techniques, used reflective probes to encourage respondents to clarify and expand on their statements. All interviews were transcribed verbatim.

\section{Data Analysis}

We analyzed transcripts using an "editing organizing style," a qualitative analysis technique in which researchers search for "meaningful units or segments of text that both stand on their own and relate to the purpose of the study". ${ }^{13}$ With this method, the coding template emerges from the data, as opposed to the application of a pre-existing template. Two investigators independently analyzed the transcripts, generated codes to represent the informants' statements, and created a coding template. In cases of discrepant coding, the two investigators successfully reached consensus after reviewing and discussing each other's coding. Atlas.ti 5.0 software (Atlas.ti GmbH, Berlin, Germany, 2005) was used for data management and analysis. The authors agreed on representative quotes for each theme.

Following accepted qualitative methodology, we discontinued sampling after 24 interviews, when it was determined that new interviews yielded confirmatory rather than novel themes, a process called achieving "thematic saturation". ${ }^{13}$ This sampling size is consistent with other published qualitative studies. ${ }^{2,14-17}$

\section{RESULTS}

Informant Sampling and Respondent Demographics

Two department of medicine chairs did not respond to our requests for the names of the most clinically excellent physicians among their faculty. Of the 40 names provided by the other eight Chairs, 24 (three from each AMC) were randomly selected for the study. Of these, 2 individuals were not able to make time for participation; however, at both institutions, the next physician was agreeable.

Twenty-four of the 26 physicians approached (92\%) participated in 30-minute interviews. The majority of the participating physicians $(83 \%)$ were associate professors or professors, one third (33\%) were women, and the informants hailed from a diverse range of specialties of internal medicine (table 1). 
Table 1. Characteristics of the 24 clinically excellent physicians from 8 academic institutions with highly rated departments of medicine.

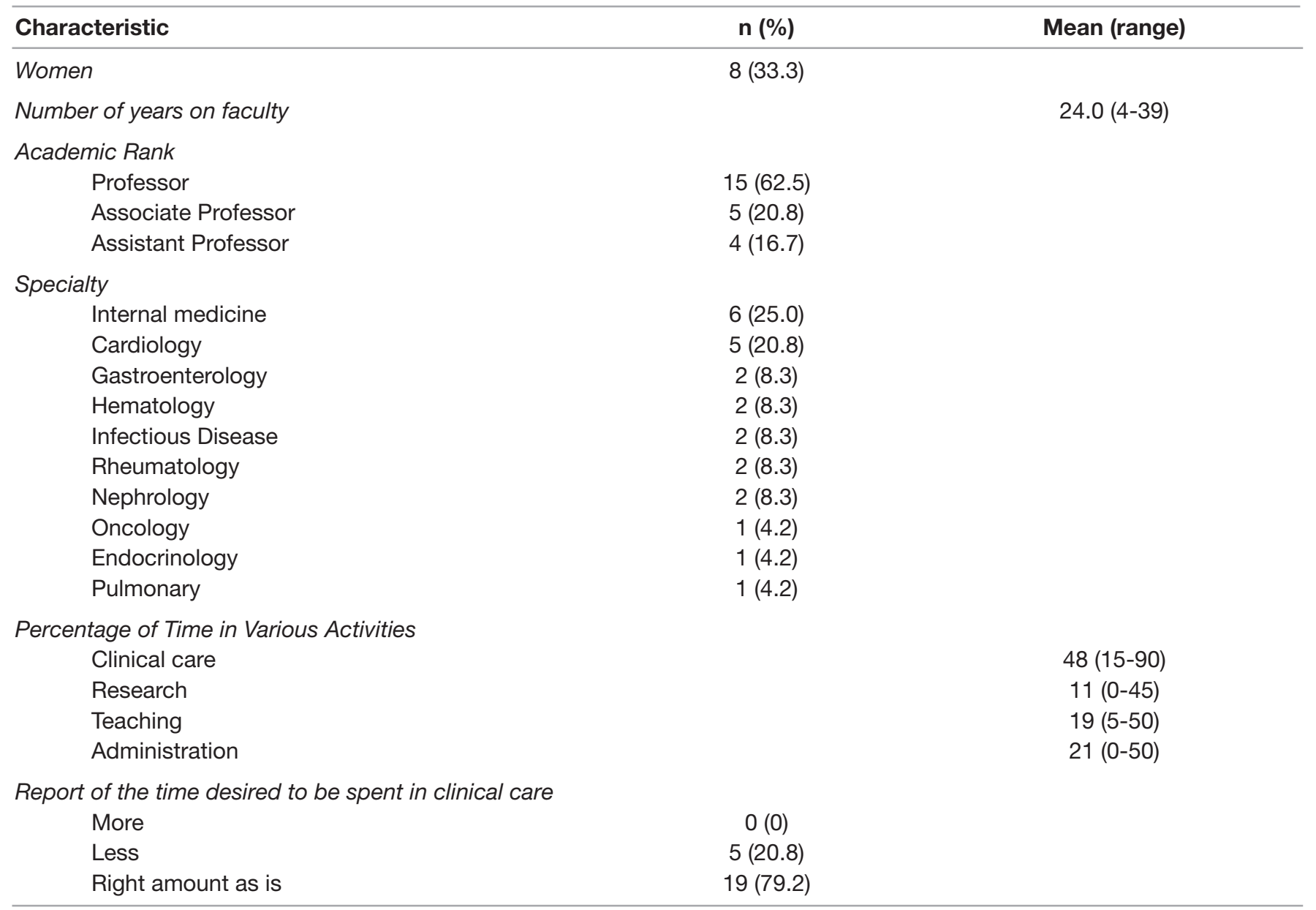

In describing their current clinical efforts, the average percent time spent on clinical care was $48 \%$. Most informants $(19 ; 79 \%)$ reported that they felt like their clinical effort was just the right amount of time to spend in clinical work while the other $5(21 \%)$ reported a preference to decrease their clinical time.

\section{Results of Qualitative Analysis}

The comments and stories told by the physician informants were categorized into domains that describe and relate to the failure to recognize clinical excellence in academia. The five themes that emerged are presented in table 2, along with the number of times each was mentioned as well as the percent of informants referring to the theme.

\section{Low Morale and Prestige of Clinicians}

The most frequently cited idea, referred to by 14 respondents, was the notion that physicians in academic medical centers whose primary activity is clinical care have depleted morale and low prestige relative to their peers primarily engaged in non-patient care activities. Several respondents expressed the opinion that institutional leaders and non-clinical peers consider clinicians to be expendable. Furthermore, a number of informants felt that such attitudes are pervasive and can be sensed by students and residents, thereby undermining the value of this career path.

An oncologist who spends $75 \%$ of her time seeing patients stated:

"I think to some extent our institution considers people who see patients most of the time to be dispensable, replaceable..."

An assistant professor in gastroenterology explained her views about how the clinical faculty feel:

"I think that most clinicians do not feel valued."

A male professor in the division of nephrology described the impact of low prestige on the recruitment and retention of clinically excellent trainees and junior faculty:

"...the fellows and the junior faculty are saying that the hours are long, the pay is low, and the respect negligible, so what's to keep you here?"

Less than Excellent Patient Care

The failure to recognize and reward clinical excellence was 
Table 2. Total number of times and number of respondents referring to the major themes related to the implications of failing to recognize clinical excellence in academia, from interviews with 24 clinically excellent faculty physicians at 8 academic institutions. *

\section{Theme}

Total number of times theme mentioned in all interviews
Number of respondents referring to theme (\%)

\begin{tabular}{lcc}
\hline Low morale and prestige of clinicians & 28 & $14(58)$ \\
Less than excellent patient care & 16 & $8(33)$ \\
Loss of talented clinicians & 15 & $10(42)$ \\
Lack of commitment to improve patient care systems & 14 & $12(50)$ \\
Fewer excellent clinician role models to inspire trainees & 6 & $6(25)$
\end{tabular}

${ }^{*}$ Respondents were not queried specifically about these themes and these counts represent spontaneous and unsolicited responses in each subcategory.

thought to translate into suboptimal patient care as the system encourages faculty members to focus on non-clinical pursuits, particularly research. Patients are negatively affected by reduced access to physicians and diminished continuity. Divisional priorities and strategic plans were believed to concentrate more on discovery or advancing science and less on the delivery of top-notch clinical care.

A senior cardiologist who now spends $85 \%$ of his time in direct patient care stated:

"I think that the lack of recognition discourages people who are vested in clinical care from spending time they need in that arena because they realize that they will not be promoted."

This same physician went on to say:

"Our internists have been marginalized. They have been moved off-site ...the patient is getting lost in the shuffle. Communication between attendings is virtually nonexistent."

An assistant professor internist emphasized that patients are the ones who lose out:

"I think it is very important to reward good clinicians to stay in the medical center, because they are really the glue that holds patient care together. Without the continuity that they provide and the accessibility... care gets fragmented..."

\section{Losing Talented Clinicians}

This theme, loss of clinically excellent physicians to academia, was cited 15 times by 10 respondents (42\%) (table 2). The failure to recognize clinical excellence was thought to be responsible for difficulties in recruiting clinical stars to join the faculty, such as chief residents. In addition to those that that never sign on, it was believed that excellent clinicians are difficult to retain in academia because they soon come to realize that their talents will be more appreciated and respected in non-academic settings. This latter observation results in increased physician turnover, which is both costly and disruptive to patient care.

A nephrologist who spends $40 \%$ of his time in patient care explained:

"There are a number of individuals who are practicing in the area who would probably still be on [the] full-time faculty if there was a way for them to be supported and recognized adequately."

A male general internist stated:

"We have lost some really good faculty members. I know of three or four chief residents that... left because of [this] particular issue."

A professor in rheumatology expressed his belief that the more junior faculty members are most vulnerable:

"The people at risk for being lost are not those who are considered master clinicians, it's the junior faculty, the clinical instructors, the assistant professors, the mid-early career associate professors, who are not being rewarded for clinical skills..."

\section{Lack of Commitment to Improve Patient Care Systems}

The physician informants believed that the failure to recognize clinical excellence at academic medical centers reduces the motivation for physicians to invest their energy, creativity, and time into improving the health care system. They explained that personal investment is highly correlated with incentives and rewards. As such, academic physicians do not feel compelled to enhance systems that may allow for better patient care.

A female endocrinologist who spends $50 \%$ of her time in clinical care explained the dedication that is required to ameliorate care processes:

"Systems improvement takes a lot of time." 
A male rheumatologist clarified why it is so hard to improve clinical outcomes and systems when clinical excellence is not rewarded:

“...the greater loss of not recognizing clinical excellence is the failure to maximize clinical excellence-if you are not rewarded, if no one is measuring it... then it is very hard to make improvements in this arena."

A male cardiology assistant professor who spends $60 \%$ time in clinical practice rationalized that the lack of investment to support clinical excellence stifles or restricts best practice:

"We do not have the infrastructure to support great clinicians because we've been so focused on research... We are a little naïve about what it takes to actually make clinically excellent doctors."

Fewer Excellent Clinician Role Models to Inspire Trainees Informants understood and detailed how faculty role models influence career choices. They described that the failure to recognize clinical excellence in academic medical centers alters both the quantity and quality of clinical role models to inspire the physicians of tomorrow.

A female general internist described the opportunity cost:

"Loss of clinically excellent physicians affects training our house staff, we lose role models."

An assistant professor reflected back on his days as a trainee:

"There were 2-3 people during my fellowship that had the most impact on me... and those people I think were underrecognized. I sort of know how they felt now having been through that."

An infectious diseases Professor explained:

"I advocate for improvement in clinical care as I advocate for improvement in education... To train better students and better residents we have to have role models that live that promise... They are... the perfect examples for trainees to learn from."

\section{DISCUSSION}

Fiscal realities have made strong clinicians valuable to academic medical centers; these physicians draw patients to the institution. Therefore, it is necessary to develop mechanisms to recognize and retain outstanding clinicians. This qualitative analysis of in-depth interviews with clinically excellent academic physicians reveals five notable consequences related to the failure to recognize clinical excellence in academic medicine. The emergent themes impact upon how academic clinicians view themselves and are perceived by others (low morale and prestige among clinicians); the quality of patient care delivered (less than excellent patient care and the lack of commitment to improve patient care systems); the pool of physicians delivering the care (loss of talented clinicians); and our institutions' educational capacities (fewer excellent clinician role models to inspire trainees). This failure most clearly threatens two of the pillars of academic medicine's tripartite mission: delivery of humane, patient-centered care, and educating the next generation of physicians. The third pillar, research, may also be compromised to the extent that new discoveries often grow out of astute clinical observations made at the bedside and subsequent interaction between clinicians and researchers. Further, the interface between these groups may also help in the translation of new science into clinical practice.

The consequences that are believed to have resulted from this lack of recognition may have been predicted based on motivational theory. ${ }^{18}$ Motivation is defined as "the power to move or excite individuals to action". ${ }^{19}$ It had been shown that the extrinsic rewards noted to motivate academic physicians include the prospect of a stable, secure future and the attainment of social status and prestige.$^{20}$ Because of the income differential between academia and the private sector, even if academic clinicians were revered and promoted on this basis, that would not be enough to retain many. That said, the fundamental extrinsic reward in academic medicine is promotion which is determined predominantly by success along research metrics. $6,9,11$ Academic physicians are thus naturally drawn to activities that will result in scholarship, thereby optimizing their likelihood of being promoted.4,11,21 In any field, smart individuals will take note of what is rewarded and will direct their activities accordingly. ${ }^{22,23}$ As a result, many academic faculty elect to limit their time spent in teaching and in clinical care so as to spend greater time on the activity that brings acknowledgement and reward.,2,24

The faculty are a medical school's most precious resource, and therefore, all should be made to feel valued and appreciated. Further, recruitment of new talent is difficult and costly. Therefore, retention becomes an important strategy for conserving and building academic programs. Faculty satisfaction is associated with retention. ${ }^{25,26}$ A study by Lowenstein and colleagues 5 revealed that physicians who spend more time in clinical care are less committed to academic careers. One predictor of a "serious intent to leave academia" was feeling that there was lack of recognition of clinical work in promotion considerations. ${ }^{5}$ With respect to the educational consequences, medical trainees (students, residents, and fellows) aspire to emulate role model clinicians. ${ }^{14,27-29}$ Thus, supporting the careers of clinically excellent faculty in academia and recognizing their talents are essential not only for satisfying patient desires, but also for the enrichment of medical education.

Selection of the study sample is critically important when using qualitative methodologies. ${ }^{13}$ We purposively sought out the perspectives of 'expert clinicians' at leading medical institutions, although the top centers as ranked by U.S. News 
and World Report are so determined using a metric based largely on overall institutional prestige and research prowess. ${ }^{12}$ Our informants were experienced academic clinicians, many of whom have witnessed changes over decades and have seen shifts in institutional priorities over time, thereby making them an optimal cohort to query in depth. It is certainly possible that the themes that emerged from the analysis may have been different if we would have interviewed physicians with lesser reputation at these same institutions, or if we studied the faculty at AMC's with less research prominence. The data collection method used (semi-structured interviews) allowed for the generation of hypotheses and the identification of important issues. Because the goal of the study was to understand the range of consequences resulting from the failure to recognize clinical excellence at AMC's, as opposed to prioritizing the resultant consequences relative to one another, we designedly elected not to use a nominal group process or a modified Delphi approach.

Several limitations of this study should be considered. First, this study relied exclusively on self-report. However, this is considered to be the most direct approach for understanding attitudes and beliefs. Second, this qualitative study is limited to a small number of clinically excellent physicians at eight AMCs within the department of medicine, and as such our findings may not apply to other institutions or departments. It is also possible that the department chairs may not be accurate in their perception of who are the top clinicians. Third, two physicians declined participation, and it is possible that their perspectives may have been different. Finally, the frequency with which many of the themes were described by informants was less than fifty percent. However, it is important to note that the responses emerging from the open-ended question were spontaneous. Qualitative analysis does not really allow us to know whether one theme is more important than another merely because it was mentioned more frequently. If all subjects were specifically asked about each theme, the number of comments related to each would certainly be much higher.

\section{CONCLUSION}

Clinically excellent physicians are valuable to academic medical institutions and cannot be made to feel as an expendable resource. The public trust and the future of academic medicine are at stake if the reward system continues to solely reward researchers and disregard the clinicians. Organizations hoping to recruit and retain clinically excellent physicians or to advance and cultivate their clinical missions may need to rethink their reward systems.

\section{ACKNOWLEDGEMENTS}

Drs. Christmas, Kravet, Durso, and Wright are MillerCoulson Family Scholars. Dr. Wright is an Arnold P. Gold Foundation Professor of Medicine. This work is supported by the Miller-Coulson family through the Johns Hopkins Center for Innovative Medicine.

\section{REFERENCES}

1. Yusuf SW. The decline of academic medicine. Lancet 2006; 368:284.

2. Christmas C, Kravet SJ, Durso SC, Wright SM. Clinical excellence in academia: perspectives from masterful academic clinicians. Mayo Clin Proc 2008;83:989-994.

3. Schroeder SA, Zones JS, Showstack JA. Academic medicine as a public trust. JAMA 1989;262:803-812.

4. Atasoylu AA, Wright SM, Beasley BW, Cofrancesco J, Macpherson D, Partridge T, Thomas, PA, Bass EB. Promotion criteria for clinician-educators. J Gen Int Med 2003;18:711-716.

5. Lowenstein SR, Fernandez G, Crane LA. Medical school faculty discontent: prevalence and predictors of intent to leave academic careers. BMC Med Educ 2007;7:37.

6. Batshaw ML, Plotnick LP, Petty BG, Woolf PK, Mellits ED. Academic promotion at a medical school. Experience at Johns Hopkins University School of Medicine. N Engl J Med 1988;318:741-747.

7. Barondes JA. The academic health center and the public agenda: whose three-legged stool? Ann Intern Med 1991; 115:962-967.

8. Carey RM, Wheby MS, Reynolds RE. Evaluating faculty clinical excellence in the academic health sciences center. Acad Med 1993;68:813-817.

9. Bickel J. The changing faces of promotion and tenure at U.S. medical schools. Acad Med 1991;66:249-256.

10. Stossel TP. Volume: papers and academic promotion. Ann Intern Med 1987;106:146-149.

11. Beasley BW, Simon SD, Wright SM. A time to be promoted: The Prospective Study of Promotion in Academia (Prospective Study of Promotion in Academia). J Gen Intern Med 2006;21:123-129.

12. America's best graduate schools. U.S. News and World Report 2006:36.

13. Crabtree BF, Miller WL. Doing qualitative research. 2nd ed. Thousand Oaks, CA. Sage Publications; 1999.

14. Wright SM, Carrese JA. Excellence in role modeling: insight and perspectives from the pros. CMAJ 2002; 167:638-643.

15. Schonberg MA, Ramanan RA, McCarthy EP, Marcantonio ER. Decision making and counseling around mammography screening for women aged 80 or older. J Gen Intern Med 2006;21:979-985.

16. Green ML, Ruff TR. Why do residents fail to answer their clinical questions? A qualitative study of barriers to practicing evidence-based medicine. Acad Med 2005;80:176-182.

17. Ratanawongsa N, Teherani A, Hauer KE. Third-year medical students' experiences with dying patients during the internal medicine clerkship: a qualitative study of the informal curriculum. Acad Med 2005;80:641-647.

18. Herzberg F. One more time: How do you motivate employees? 1968 Harv Bus Rev. 2003;81:87-96.

19. The American Heritage Dictionary of the English Language. 3rd ed. Boston, Mass: Houghton Mifflin; 1992.

20. Wright SM, Beasley BW. Motivating factors for academic physicians within departments of medicine. Mayo Clin Proc 2004;79:1145-1150.

21. Thomas PA, Diener-West M, Canto MI, Martin DR, Post WS, Streiff MB. Results of an academic promotion and career path survey of faculty at the Johns Hopkins University School of Medicine. Acad Med 2004;79:258-264.

22. Ratanawongsa N, Howell EE, Wright SM. What motivates physicians throughout their careers in medicine? Compr Ther 2006;32:210-217. 
23. London M. Toward a theory of career motivation. Acad Manage Rev 1983;8(4):620.

24. Lanier WL, Rose SH. The contemporary medical community: leadership, mentorship, and career choices. Mayo Clin Proc 2008;83:974-977.

25. Demmy TL, Kivlahan C, Stone TT, Teague L, Sapienza P. Physicians' perceptions of institutional and leadership factors influencing their job satisfaction at one academic medical center. Acad Med 2002; 77:1235-1240.

26. Buckley LM, Sanders K, Shih M, Hampton CL. Attitudes of clinical faculty about career progress, career success and recognition, and commitment to academic medicine. Results of a survey. Arch Intern Med 2000;160:2625-2629.

27. Bendapudi NM, Berry LL, Frey KA, Parish JT, Rayburn WL. Patients' perspectives on ideal physician behaviors. Mayo Clin Proc 2006;81:338-344.

28. Chang JT, Hays RD, Shekelle PG, MacLean CH, Solomon DH, Reuben DB, Roth CP, Kamberg CJ, Adams J, Young RT, Wenger NS. Patients' global ratings of their health care are not associated with the technical quality of their care. Ann Int Med 2006;144:665-672.

29. Wright SM, Kern DE, Kolodner K, Howard DM, Brancati FL. Attributes of excellent attendingphysician role models. N Eng J Med 1998; 339:1986-1993.

\section{AUTHOR AFFILIATIONS}

Samuel C. Durso, $M D, M B A^{*}$;

Colleen Christmas, $M D^{*}$;

Steven J. Kravet, $M D, M B A^{\dagger}$;

Gregory Parsons ${ }^{\dagger}$;

Scott M. Wright, MD';

Divisions of Geriatrics* and General Internal Medicinet

Johns Hopkins Bayview Medical Center

Johns Hopkins University School of Medicine

Baltimore, Maryland 